\title{
Online Databases and the Research Experience for University Students with Print Disabilities
}

Kelly Dermody

Ryerson University

Norda Majekodunmi

York University

digital.library.ryerson.ca/object/293

Please Cite:

Dermody, K., \& Majekodunmi, N. (2011), Online databases and the research experience for university students with print disabilities. Library Hi Tech, 29(1), 149-160.

doi: $10.1108 / 07378831111116976$

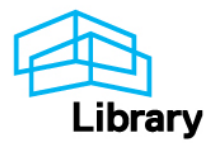




\section{Title}

On-line databases and the research experience for university students with print disabilities.

\section{Autobiographical note:}

Kelly Dermody

Ryerson University Library and Archives, Toronto, Ontario, Canada

kdermody@ryerson.ca

Ryerson University

350 Victoria Street, LIB 395

M5B 2K3

Norda Majekodunmi

York University Libraries, Toronto, Ontario, Canada

nordam@yorku.ca

York University

4700 Keele Street

Scott Library, Rm 205

M3J 1P3

\section{About the Authors}

Kelly Dermody is the Coordinator of Library Services for Persons with Disabilities at Ryerson University Library and Archives, Toronto, Ontario, Canada. She can be contacted at: kdermody@ryerson.ca

Norda Majekodunmi is an Assistant Librarian at Scott Library, York University, Toronto, Canada. She also serves as the Liaison to Library Accessibility Services. 
On-line databases and the research experience for university students with print disabilities

The $21^{\text {st }}$ century higher education institution reflects an increasingly diverse student population. The disability rights community in Canada has long fought for the rights of person with disabilities to participate fully in all aspect of society including the pursuit of higher education. While recent reports indicated that persons with disabilities are still on the economic margins of Canadian society, more and more students with disabilities are graduating from higher education institutions (Statistics Canada, 2008). There is no doubt that technology has opened the door for students with disabilities. From screen readers to augmentative communication programs, persons with disabilities can attend classes, participate in discussions, and read and write assignments independently. However, as many students who rely on assistive technology know, technology can also be a barrier. The advances in Web 2.0 and the new virtual learning environment does not always take into consideration whether or not it is compatible with the assistive technology students rely on. This study in particular looks at the impact the evolving nature of library databases have on students with print disabilities who use screen reading software to navigate their on-line learning. Screen reading software reads the contents of a computer screen by converting text to speech.

The academic library in Canada has largely shifted from being a storehouse of predominately print resources to a digital library with an abundance of online resources in the form of electronic journals, ebooks and online databases. On-line resources means greater access to information for students with print disabilities. However, while most libraries have successfully addressed the issues of physical barriers in their library, identifying and removing barriers to electronic resources still poses a challenge to academic libraries (Riley, 2002; Saumure and Given, 2004). This study aims to investigate the impact of library database design on students who use screen readers. In 
particular, this study sets out to see what barriers are preventing students from completing the first step of the information gathering process - locating and selecting appropriate articles - and what are the consequences if any for these students.

\section{Literature Review}

Various studies indicate that students with disabilities experience unique challenges when accessing library resources (Riley, 2002; Byerley and Chambers, 2002; Coonin, 2002). Students who rely on screen readers are experiencing barriers accessing information due to the rich graphical interfaces and complex web designs of proprietary online databases (Horwath, 2002). Stewart et al., (2005), Bowman (2002), and Byerley and Chambers (2002) tested the accessibility of specific electronic databases with screen reading software and found they were not user-friendly. Howarth (2002) surveyed users who were blind or visually impaired on the usability of four databases and found that the design had the greatest impact on the accessibility of the databases. Stewart at al., (2005) evaluated 37 database interfaces with adaptive software and checked for compliance with web content accessibility guidelines. The study's six sighted students were trained to evaluate the interfaces, but these students were not native users of the adaptive software studied. One research limitation acknowledged in this study was that it did not focus on the difficulty involved in performing searches and the accessibility of document content. Riley (2002) tested three prominent library databases using four types of screen readers. A sighted librarian tested databases with the screen readers using the guidelines recommended by the Web Access Initiative (WAI section of the World Wide Web Consortium). Byerley and Chambers (2002) examined the use of two databases (OCLC First search and Expanded Academic) by blind students using screen readers. Web content accessibility guidelines were used as a measurement of accessibility. They found again that design elements in both databases compromised the accessibility of the databases. 
A more recent study by Byerley et al., (2007) examined the accessibility of online databases from the database vendors' perspectives. They found that vendors rated their products as mostly accessible. The study determined that although most vendors test their products for accessibility, only a few conducted usability tests with actual persons with disabilities using adaptive technology. This 2007 study from the vendor's perspective influenced the authors to conduct their own test using students with print disabilities.

There are various studies on the importance of information literacy instruction and its impact on the research skills of university students (Zoellner et al., 2008; Bruce 1998; Mittermeyer, 2003; Valentine, 2001; Nowicki, 2003). Studies by Mittermeyer (2003) and Nowicki (2003) demonstrated that students as a general population have significant limited knowledge of the basic elements of research and database searching. Head and Eisenberg's 2009 study indicated that students draw on the same few information resources and preferred sources for their "brevity, consensus, and currency over other qualities and less so, for their scholarly authority" (p. 21).

An extensive search produced only one study on the information behaviour of visually impaired students. Samure and Given (2004) indicated that the information seeking behavior of visually impaired students required additional time to ensure the material was accessible. Unlike students who were not visually impaired, students in Samure and Given's study indicated they had to go back and forth with their disability office to ensure the article or book was accessible, and that they relied on interpersonal contacts like librarians, friends and counselors to ensure they could access information. Therefore the students lacked independence in their information seeking behavior. Students also indicated they looked for readily available sources on the internet. Relying on accessible information reduced the amount of resources they could have use for their research. 
An extensive search produced no studies on the literacy skills of higher education students with print disabilities. There was also no studies on the intersection of inaccessible databases and its impact on the literacy skills of students with visual or print disabilities. While this study concentrates on the first step in the information process - gathering information, the impact on information literacy highlights an area that requires more research.

\section{Purpose}

This research paper will report on the findings of a study which traces the research process of a small sample of 10 Canadian university students with print disabilities who use screen readers to access information online. The study aims to answer several questions:

a) Can students navigate these electronic resources independently and locate and select articles for their research?

b) Are students who use screen readers using enhanced features in online databases to help them select relevant and scholarly articles?

c) What kinds of accessibility barriers, if any, are encountered during the research process?

\section{Methodology}

This qualitative study observed the execution of a database search by students with print disabilities who use screen readers to access information online. For the purpose of this study, we have used the definition of perceptual disability from the Canadian Copy Right Act to define Print disability (Copyright Act , 1985).

A total of 10 undergraduate and graduate students at Ryerson University and York University participated in this study. Both universities are located in Toronto, Canada. York University is the third largest university in Canada with a student population close 
to 52,000 in 2008; approximately 2000 students were registered with support services for students with disabilities. Ryerson University is located in the city's urban center and has a population of close to 28,000 students; approximately 1200 students registered with support services for students with disabilities. Participants were selected based on their response to a preliminary demographic survey. Student recruits met the criteria of having a print disability and had experience using screen reading software for at least one year.

The study was conducted in computer labs equipped with various screen readers (JAWS, Zoomtext and Kurzweil 3000) at both universities. Participants were asked to complete a series of tasks in three different online databases (CBCA Complete, Sociological Abstracts and Expanded Academic ASAP). The three databases selected represented three different vendors (ProQuest, CSA and Gale, respectively) of electronic resources commonly used by students at both universities. The vendors' perspectives study by Byerley et al., (2007) indicated that EBSCO was a proactive vendor in terms of product accessibility and therefore was not selected for this study. The order of databases searched alternated with each participant.

For each database participants were instructed to use their screen reader to:

a) Search the database for academic articles on "women with disabilities in Canada."

b) Identify two full-text scholarly articles.

c) Access the articles and read the first page of each article.

Camtasia Studio, a screen recording software, was used to record the steps of participants throughout the research process. A microphone attached to the computer also provided audio recordings of the screen readers and participants' verbal comments. An observer was also present in the room to take notes and to be available for nonresearch related assistance if needed. 
A pre-survey was administered before testing began and surveys were administered after each database search session. The pre-survey contained questions about the participant's research skills and knowledge of accessibility features. The questions from the database search survey were quantitative with a comment section for further comments and observations. Participants completed a final survey on their overall search experience after all three databases were searched. A comments section was also provided. All surveys were available in Microsoft Word format and completed electronically. In keeping with the privacy policies of both universities the students were assigned a number and their information was codified.

\section{Limitations}

Studies have shown that students in general experience difficulties with the search process in databases (Finder et al., 2006; Mittermeyer, 2005, Valentine 2001). This study focused solely on students with print disabilities and therefore lacks a control group of non-print disabled students against which the results of students with print disabilities could be measured.

A small sample size is another study limitation. Several students were concerned about privacy issues and expressed reluctance to participate in the study. A total of ten students participated in the study (with 5 from each university). This corresponds to a 4 percent representation of registered students with a print disability at Ryerson University and 2 percent representation of students at York University. The small sample size affects the generalization of results.

\section{Results}

\subsection{Demographics}

The majority of the students were undergraduates $(80 \%)$ with a vision related disability (low vision or vision loss). Students with learning disabilities represented $30 \%$ of the 
group and $10 \%$ had multiple disabilities (vision loss and learning disability). On average the students had 6.5 years of experience using screen readers.

In the pre survey, $80 \%$ of students indicated they were intermediate library users with intermediate computer skills. The majority of them $(70 \%)$ had used library databases for finding articles. Over $60 \%$ had asked for help from a librarian and on average it took them 4 hours to find articles for any particular assignment. This was not the case for all the students, as 30\% indicated that it took them on average 8 hours to find articles for one assignment. Student knowledge of the three databases was similar with $50 \%$ having used Sociological Abstracts, 40\% used CBCA Complete and 30\% used Expanded Academic prior to the study.

\subsection{Locating and Selecting Scholarly Articles}

The survey and video results show a discrepancy between how students rated their ability to navigate through the databases and locate 3 articles. A majority of students (70\%) felt they had succeeded at finishing the task. The video evidence produced different numbers.

Students entered incorrect Boolean search strategies $44 \%$ of the time. The videos showed students using colons and commas while others used "Or" instead of "And" between their search terms. The actual success rate of finding two scholarly articles according to the video evidence is only $53 \%$. While the majority (75\%) of students were able to locate the summary/abstract page of an article, the success rate fell to $55 \%$ when they tried to locate the full text and read the first page.

Of the article abstracts found only $41 \%$ were on women with disabilities in Canada, The majority $(69 \%)$ of abstracts selected where either conference proceedings, book reviews or not on the topic at all. Students indicated on their post database surveys that they considered their articles scholarly and this therefore accounts for their perspective that they completed the task. 
Students felt they had the most success (60\%) when using Expanded Academic and had the least success $(60 \%)$ when using Sociological Abstracts. Video evidence indicates that they had the best results at finding a scholarly article and reading the first page when using Sociological Abstracts but only by a margin of one. Students located 8 out of 20 scholarly and readable articles when using Sociological Abstracts and 7 when using Expanded Academic. The success rate for CBCA was 6 (See Table 1).

Table 1: Locating and Reading Full Text Articles by Database

Database Success at Locating two readable Full text articles (\%)
Success at locating two

Scholarly and readable full Text articles (\%)
Expanded Academic ASAP

CBCA Complete

Sociological Abstracts
55

70
35

30

40

When asked in the post survey, $87 \%$ of the students indicated they were aware they could limit their search by full text, date, author etc. A clear majority of $90 \%$ indicated they were aware they could limit their results to peer reviewed. Video evidence shows that students used limiters only $40 \%$ of the time and the Peer Review limiter was used $13 \%$ of the time. The $13 \%$ usage corresponds to low success rate of selecting appropriate articles ( $41 \%$ for abstracts).

\subsection{Barriers Encountered}

Overall, students rated each database's ability to retrieve and read full text articles as difficult to somewhat challenging on a scale from difficult to easy. For example, students 
rated Expanded Academic ASAP and Sociological Abstracts as difficult when it came to using their screen reader to read the full text articles (see Table 2).

Table 2. Student rating of using screen readers to complete specific tasks by database Expanded Academic ASAP

\begin{tabular}{|c|c|c|c|}
\hline Task & Easy $(\%)$ & \multicolumn{2}{|c|}{$\begin{array}{l}\text { Somewhat } \\
\text { Challenging (\%) }\end{array}$} \\
\hline Identify where to enter search terms & 50 & 30 & \\
\hline Screen-reader ability to read search results & 40 & 30 & \\
\hline Screen reader ability to retrieve full-text & 50 & 20 & \\
\hline Screen reader ability to read full-text & 30 & 10 & \\
\hline Navigate the database & 40 & 40 & 20 \\
\hline Overall search experience & 40 & 20 & 40 \\
\hline
\end{tabular}

CBCA Complete

Task

Easy (\%) Somewhat Difficult (\%) Challenging ( $\%)$

Identify where to enter search terms 60 $60 \quad 40 \quad 0$

Screen-reader ability to read search results 20

$20 \quad 60$

Screen reader ability to retrieve full-text $\quad 30$

$30 \quad 40$

Screen reader ability to read full-text $\quad 50$

$0 \quad 50$

Navigate the database

30

40

30

Overall search experience

30

30

40 
Sociological Abstracts

Task

Identify where to enter search terms

Screen-reader ability to read search results

20

Screen reader ability to retrieve full-text

Screen reader ability to read full-text

Navigate the database

Overall search experience

Easy (\%)

60

20

40

\section{Somewhat Difficult (\%) Challenging (\%)}

30

20
30

30

30

$\begin{array}{ll}0 & 70\end{array}$

$30 \quad 10 \quad 60$

$\begin{array}{lll}30 & 50 & 20\end{array}$

$\begin{array}{lll}20 & 50 & 30\end{array}$

As mentioned above the success rate of students finding two readable articles was only $55 \%$ and the largest reason for students not completing the task (32\%) was due to the accessible barriers they encountered while searching. The other reasons (13\%) were due to negative article results such as articles only available through Inter-Library Loan or students abandoning their search after they entered incorrect Boolean and received 0 results. One common example of an accessibility barrier from the video evidence was when students selected an article in PDF that was inaccessible. The PDFs were image based and were not tagged for screen readers. Stewart et al., (2005) noted in their study that vendors "are at the mercy of the contributing journal publishers who may provide the...content in an accessible or inaccessible format" (p. 275). In our study one student indicated in the pre survey, "my biggest fear is finding the perfect PDF document for a research project but not having it be in an OCR format, meaning that I cannot use a screen reader to read it." Video evidence also shows two students spending up to 10 minutes trying to locate the full text link on the summary page. Their screen reader was unable to read the link back to them because it was image based and not labeled with 
html full text. Again, the students had to abandon the article and return to the search page to locate another article. The screen reader's inability to find the link to the full text article occurred 10 times out of 60 searches (17\%), while inaccessible PDFs occurred nine times (15\%).

In the comment section of the surveys, students indicated their frustration at the barriers they encountered. Students indicated frustration with the search process and their comments ranged from: "I don't really know what I'm doing. I spend a lot of time and sometimes end up with nothing" to "I find it difficult and time consuming it seems to take longer for me than for others."

Students indicated that the amount of links on the result page in all three databases was a barrier and interfered with their screen readers. Video evidence shows that screen readers would read each link on the page (in some cases there were over 25 links on a page). Students indicated in their comments that the amount of links leads to confusion and makes searches longer. As one student put it: "for every extra... button that can be clicked, the likelihood of people becoming confused increases. The more busy a database interface may be, the risk increases of [screen readers] not being able to keep pace."

\section{Discussion}

This study takes a student centered approach. The aim was to see how database design and screen reading technology impact a student's ability to gather information, which is the first step in completing their research assignments. The study set out to answer questions on how students navigate databases using screen readers, what features they are missing and what barriers they encounter. The results show that students' ability to locate articles is compromised by two factors; 
a) the design barriers in databases and the limitation of screen reading software and

b) lack of training and knowledge on how to be effective searchers while using screen readers.

\subsection{Design of Databases and Screen Readers}

Technology is both an enabler and a barrier for students with print disabilities. While screen readers enable students to navigate their on-line environment, they are limited in how they can interpret a busy website. While database and website design is evolving to the benefit of users, the contradiction is that these enriched features which create greater accessibility to information also creates barriers for students who rely on screen readers. The results of the above study summarize what Comeaux and Schmetzke indicated in their 2007 study that "for users with print disabilities, design in the on-line world matters as much as it does in the physical world" (p. 458).

The students in this study did work their way through the three databases in question and the success rate of finding two readable articles was 55\%, but video evidence demonstrates that students encountered barriers such as inaccessible PDFs, unreadable links and too many links. This cut their success rate by $32 \%$. They rated their experience of searching with a screen reader as either difficult or somewhat challenging and their comments showed a high level of frustration. As Byerley et al., put it in their 2007 study, "it may be technically possible for people who use screen readers to perform a given task, but it does not mean they can execute the task gracefully" (p. 526).

This study suggests that the students tested were not benefiting from the enriched links and other features offered by all three databases; they were in fact being impaired by them. Their comments suggest that in order for them to find the articles they need, they require a simplified search interface and clear and proper placement of full text links. 
Two of the students commented that they enjoyed using Google Scholar because of its simple search interface over the three databases. Haya et al., (2007) also found that students overwhelming praised Google Scholar's interface for its simplicity and familiarity. Another aspect that students commented on was that the databases offered them no recourse when they came across an unreadable PDF. They simply had to close it and walk away from the article.

Database vendors are aware of the barriers their databases pose for users who rely on screen readers. Vendors like Gale and Proquest provide formal accessibility statements on their websites. The databases offered by Ebscho Host and Proquest offer an accessible search interface for screen readers (Byerley et al., 2007). However, Byerley et al., (2007) indicated in their study that vendors are not addressing accessibility in their marketing efforts. During our testing, the link to the accessible search screen in Proquest CBCA was available to students to use, but none of the students used the text-only search interface. This supports what was indicated in the pre-survey where $80 \%$ of the students indicated they were unaware of any accessible options in databases. One explanation is that the link, which is at the bottom of the page, is not visible enough for the students to notice, nor is it being advertised by the database company or the libraries in this study.

The 2007 study by Byerley et al., indicated that only 5 of the 12 vendors (EBSCO, Elsevier, JSTOR, LexisNexis, ProQuest) surveyed conducted usability testing with people who have visual disabilities. ProQuest was the only database from the 3 selected for this study that asked users who were blind to test their products. This study indicates that database vendors need to continue to investigate and promote accessible interfaces. There is also a need to investigate what recourses are available to students who come across inaccessible PDFs. Furthermore, the study demonstrates that databases searching is challenging for students who have visual and learning disabilities. The students in our study with learning disabilities had the same results as those with a 
visual disability. Due to the nature of their learning disability, they relied on their screen reader to interpret the text on the screen for them. Their comments and the video evidence indicated that they were affected by the amount of links and labelling practices in all three databases. This study indicates that further testing is needed with users who rely on screen readers, but it also indicates that research participants should include those with visual disabilities and other print-related disabilities like learning and mobility.

It is in the best interest of vendors to assist libraries in advertising the accessible features in their databases. The academic library also plays a role in lobbying for accessible databases. As buyers of databases, libraries can incorporate questions on accessibility in their procurement policies. Through their procurement policies they can indicate to the vendors that they rank accessibility as a high selling point. The library can also assist the database vendors in usability feedback and in marketing accessible options that are available. Partnering for accessibility will benefit all three stakeholders in this study: students, vendors and academic libraries.

\subsection{Factor Two: Library Instruction}

Students in our study receive accommodations from their university to help them achieve their academic success. By leveling the playing field through specialized accommodations, student achieve the same success through hard work and study as their non-disabled peers. The library also plays a role in assisting students with disabilities achieve their academic success.

Studies have shown that information literacy is a critical element in fostering problem solving and independent learning in higher education students (Bruce, 1998; Shapiro and Hughes, 1996). The question this study asked was whether the barriers in database design can affect a student's information gathering process. The results would point to yes, the first step in information literacy - the ability to critically locate and select 
appropriate articles is being compromised. The students in our study were forced to abandoned articles because of technological barriers and this limited the amount of resources they could use to write their assignments. Only the intervention of a librarian or peer would have allowed them to continue in locating the full text and reading the article. Their self efficacy as independent learners is challenged every time they encounter an unreadable PDF or take up to eight hours to find four articles.

In her 2005 study, Weiler indicated that the way students view their information universe affects their ability to develop critical thinking. Students in this study indicated that they had asked for help from a librarian (60\%) and over $80 \%$ had received library instruction in one of their classes. The results suggest that the instruction did not have a positive effect on their search skills. As one student put it, "I don't really know what I'm doing. I spend a lot of time and sometimes end up with nothings."

The results show that the majority of students had difficulty executing Boolean searches (46\% success), using limiters (36\%) and choosing appropriate articles (41\%). This study demonstrated that there is a need to investigate what type of instruction students with print disabilities require. Studies like Zoellner (2008) indicate the importance of instruction and how it can increase the confidence of students in conducting research but there is no study on whether library instruction tailored to the unique needs of students who use screen readers will increase their confidence and improve their search strategies.

Through further investigation and consultation with students who use screen readers, academic librarians can play an important part to minimize barriers in database searching. Saumure and Given (2004) indicated that students with visual disabilities rely on librarians to retrieve and locate materials in the library. The 2009 article by Power and LeBeau supports this and suggests that academic reference librarians can provide students who use screen readers training sessions on how to navigate library databases. 
Riley (2002) also suggested that tailored instruction sessions on strategies for searching databases with screen readers will help students with print disabilities master the research process.

As one student put it, "it has been difficult for me to find the right articles for my papers without relying on library support, but it is getting easier for me to do some of the research on my own as I am learning to become more adept at using the resources."

\section{Conclusion}

The digital collection of articles, books and resources provides greater access to resources 24/7 for our students. Various sectors are benefiting from digital access like distance education students and to a certain extent, students with print disabilities. While the print collection of a library is usually inaccessible to students with print disabilities, a database that can offer accessible features like simplified search screens will mean instant access to resources. As the digital information world continues to grow and offer more and more features for its users, it must also evolve to take into consideration the needs of these students. The Academic library and database vendors must work together to ensure technology opens up doors and tears down walls. To allow barriers to exist in this technological advance age would prove to be the greatest failure of the $21^{\text {st }}$ century library. 


\section{Bibliography}

Bruce, C. (1998), "The phenomenon of information literacy", Higher Education Research $\mathcal{E}$ Development, Vol.17 No. 1, pp. 25-43.

Byerley, S.L. and Chambers, M.B. (2002), "Accessibility and usability of web-based library databases for non-visual users", Library Hi Tech, Vol. 20 No. 2, pp. 169-178.

Byerley, S.L., Chambers, M.B. and Thohira, M. (2007), “Accessibility of web-based library databases: the vendors' perspectives in 2007" Library Hi Tech, Vol. 25 No. 4, pp. 509-527.

Chapman, A. (2007), "Resource discovery: catalog, cataloging and the user", Library Trends, Vol. 55 No. 4, pp. 917-931.

Comeaux, D., and Schmetzke, A. (2007), "Web accessibility trends in university libraries and library schools", Library Hi Tech, Vol. 25 No. 4, pp. 457-477.

Copyright Act, R.S. c. C-42 (1985). Available at http://laws.justice.gc.ca/en/C42/index.html (accessed 29 April 2010).

Finder, L., Dent, V.F., and Lym, B. (2006), "How the presentation of electronic gateway pages affects research behavior", The Electronic Library, Vol. 24 No. 6, pp. 804-819.

Haya, G., Nygren, E., and Widmark, W. (2006), “Metalib and Google Scholar: a user study", Online Information Review, Vol. 31 No. 3, pp. 365-375.

Head, A., and Eisenberg, M.G. (2009), "Lessons learned: how college students seek information in the digital age", Project Information Literacy Progress Report. The Information School, University of Washington. Available at http://projectinfolit.org/pdfs/PIL Fall2009 Year1Report 12 2009.pdf (accessed 29 April 2010).

Mittermeyer, D. and Quirion D. (2003), "Information literacy: study of incoming firstyear undergraduates in Quebec", Conference of Rectors and Principles of Quebec Universities, Quebec. Available at http://www.crepuq.qc.ca/documents/bibl/formation/studies Ang.pdf (accessed 15 March 2008).

Nowicki, S. (2003), "Student vs search engine: undergraduates rank results for relevance", Portal: Libraries and the Academy, Vol. 3 No. 1, pp. 503-515. 
Power, R., and LeBeau, C. (2009), "How well do academic library web sites address the needs of database users with visual disabilities?", The Reference Librarian, Vol. No. 50, pp. $55-72$.

Riley, C. (2002), “Libraries, aggregator databases, screen readers and clients with disabilities", Library Hi Tech, Vol. 20 No. 2, pp. 179-187.

Saumure, K, and Given, L.M. (2004), “Digitally enhanced? An examination of the information behaviours of visually impaired postsecondary students", Canadian Journal of Information and Library Science, Vol. 28 No. 2, pp. 25-42.

Statistics Canada (2008), Participation and Activity Limitation Survey 2006: Labour Force Experience of People with Disabilities in Canada, Statistics Canada, Ottawa, ON, available at: http://www.statcan.gc.ca/pub/89-628-x/89-628-x2008007-eng.pdf (accessed 10 December, 2009).

Stewart, R., Narendra, V. and Schmetzke, A. (2005), "Accessibility and usability of online library databases", Library Hi Tech, Vol. 23 No. 2, pp. 265-286.

Valentine, B. (2001), "The legitimate effort in research papers: student commitment versus faculty expectations", The Journal of Academic Librarianship, Vol. 27 No. 2, pp. 107115.

Weiler, A. (2005), "Information-seeking behavior in generation y students: motivation, critical thinking and learning theory", Journal of Academic Librarianship, Vol. 31 No.1, pp. 46-53.

Zoellner, K., Samson, S., and Hines, S. (2008), "Continuing assessment of library instruction to undergraduates: a general education course survey research project", College $\mathcal{E}$ Research Libraries, Vol. 69 No. 4, pp. 370-383. 